\title{
sciendo
}

\section{Lower Extremity Stiffness in Collegiate Distance Runners Pre- and Post-Competition}

\author{
by \\ Jake P. Tavernite ${ }^{1}$, Matthew F. Moran ${ }^{1}$
}

\begin{abstract}
Previous evidence has suggested that there is a relationship between leg stiffness and improved running performance. The purpose of this investigation was to determine how leg stiffness of runners was influenced in the 24 and 48 hour period following a cross country race. Twenty-two collegiate cross-country runners (13 males, 9 females, $19.5 \pm 1.4 \mathrm{yr}$ ) were recruited and participated in the study. Leg stiffness was assessed 24 hours before and after a race as well as 48 hours post-race. Three jumping protocols were conducted: 1) a static jump, 2) a countermovement jump, and 3) a vertical hopping test. Two embedded force plates (1000 Hz) were utilized to measure ground reaction forces for each test and a metronome was utilized to maintain hopping frequency $(2.2 \mathrm{~Hz})$. A significant main effect was found for a static jump, a countermovement jump and leg stiffness. Leg stiffness was significantly reduced 24 hours post-race (pre-race $36.84 \mathrm{kN} \cdot \mathrm{m}^{-1}, 24 \mathrm{~h}$ post $\left.33.11 \mathrm{kN} \cdot \mathrm{m}^{-1}, p<0.05\right)$, but not 48 hours post-race (36.30 $\mathrm{kN} \cdot \mathrm{m}^{-1}$ ). No significant differences were found in post-hoc analysis for the squat jump, countermovement jump height and the eccentric utilization ratio. Following a cross-country race, leg stiffness significantly declined in a group of collegiate runners in the immediate 24 hours post-race, but returned to baseline 48 hours post-race. Sport scientists and running coaches may be able to monitor leg stiffness as a metric to properly prescribe training regiments.
\end{abstract}

Key words: hopping, fatigue, running performance, neuromuscular characteristics, stretch-shortening cycle (SSC).

\section{Introduction}

During running and hopping, the body can be modeled as a spring-mass system when rebounding from the ground (Cavagna et al., 1988). Energy is stored and released from the lower extremities when they deform (Butler et al., 2003). To utilize this energy, some stiffness of the extremity is required (Butler et al., 2003). Stiffness contributes to the rebound of energy during the stretch-shortening cycle (SSC) (Butler et al., 2003). Although Watsford et al. (2010) have associated increased stiffness with injury in athletics, recent evidence suggests a relationship between increased lower extremity stiffness and enhanced athletic performance, specifically in distance running (Barnes et al., 2013, 2015; Spurrs et al., 2003). Barnes et al. (2015) reported that warming up with a weighted vest resulted in an increased running velocity as well as improved running economy. They attributed these improvements to an increase in leg stiffness. Spurrs et al. (2003) also reported an increase in leg stiffness and improved 3-km running times when male distance runners completed a 6-week plyometric training program. Similar changes in leg stiffness were reported when runners followed a 6-week hill interval program (Barnes et al., 2013). During a nine week plyometric intervention, Saunders et al. (2006) attributed improvements in running economy of highly trained runners to increased muscletendon stiffness. Arampatzis et al. (2001) evaluated leg stiffness during drop jumps and found that increased stiffness was associated with increased rebound velocity.

Many of the previously mentioned

\footnotetext{
1 - Sacred Heart University, College of Health Professions, Department of Physical Therapy E Human Movement Science, Motion Analysis Laboratory. 5151 Park Avenue. Fairfield, USA.
} 
studies suggest that increased stiffness is associated with improved running economy (Barnes et al., 2013, 2015; Saunders et al., 2006; Spurrs et al., 2003). Running economy is a factor closely related with running performance (Conley and Krahenbuhl, 1980; Conley et al., 1984). Conley and Krahenbuhl (1980) concluded that in a nationally prominent $10 \mathrm{~km}$ race, $65.4 \%$ of the variation in performance of highly trained athletes with similar maximal aerobic power (VO2max) could be explained by running economy. Since running economy is positively impacted by leg stiffness and running performance is influenced by running economy, leg stiffness is a valuable metric to assess in distance runners.

Lower extremity stiffness can be biomechanically assessed through vertical jump tests, which are relatively quick and nonstrenuous. McGuigan et al. (2006) described the eccentric utilization ratio (EUR), which is computed from performance of two types of jumps, a squat jump (SJ) and a countermovement jump (CMJ). Jump height and peak power are determined and used to compute the EUR. Another method to assess stiffness is the fivejump test (Saunders et al., 2006). With this assessment, the participant completes five straight leg jumps, while instructed to jump as high as possible and with as little ground contact as possible. Farley et al. (1991) used a similar procedure in order to estimate effective vertical stiffness (k) of the lower extremity muscle-tendon system. Due to the spring-mass model (Cavagna et al., 1988), $\mathrm{k}$ can be calculated from the vertical ground reaction force (vGRF) exerted on a force plate during ground contact time.

Although several studies have investigated changes in leg stiffness in runners in response to training or warm up procedures (Arampatzis et al., 2001; Barnes et al., 2013, 2015; Saunders et al., 2006; Spurrs et al., 2003), few studies, if any, have measured changes in leg stiffness due to competition (i.e., race). For example, Hunter and Smith (2007) measured vertical leg stiffness towards the beginning and the end of a one-hour high-intensity run. They found a non-significant decrease in leg stiffness towards the end of the race compared to the beginning. Similar to Hunter and Smith (2007), the relationship between fatigue and leg stiffness has been studied, but only within the same laboratory session (Morin et al., 2006). Current literature lacks information on the influence of fatigue on leg stiffness across multiple days especially in response to competition. Therefore, the current investigation seeks to answer the following research question: how will lower extremity stiffness change during the two days following an exhaustive competition? It was hypothesized that lower extremity stiffness would decrease significantly the day after the exhaustive competition.

\section{Methods}

\section{Participants}

Twenty-two active Division I collegiate cross-country runners (13 males, 9 females, $19.5 \pm$ $1.4 \mathrm{yr}$ ) (Table 1) were recruited, granted informed consent and volunteered for this study. Participants completed a short Health History Questionnaire prior to participation and were free of any history of major medical issues including metabolic and cardiovascular diseases, vestibular disorders, or musculoskeletal problems. All participants were members of the university's cross-country team and were medically cleared to participate in the study. In addition, any individuals who had surgery or an injury that prevented participation in physical activity within the last six months of the study were excluded. All study methods were submitted to and approved by the university's institutional review board.

\section{Design and Procedures}

To determine the changes in leg stiffness of runners in response to a cross-country race, participants were tested over the course of three sessions spread over four days (Figure 1). Three jumping protocols were conducted to access leg stiffness: 1) the SJ, 2) the CMJ, and 3) the vertical hopping test (HT). The first day of testing was conducted 24 hours prior to competition. On day two, each participant competed in a cross country race ( $5 \mathrm{~km}$ for women, $8 \mathrm{~km}$ for men). 24 and 48 hours following competition participants reported for the same testing procedure as on day one.

Each participant was familiarized with the testing procedure one week prior to testing. Each participant completed a 5-min self-paced warm-up on a stationary bike (Monark 828E; Vansbro, Sweden). Participants then performed 
three SJs and three CMJs (30 s of rest intervals between jumps) on two embedded force plates (AMTI Optima OPT464508; Watertown, MA) sampled at $1000 \mathrm{~Hz}$. The fourth jump was recorded if two jump heights in the set were outside of a threshold of $2.5 \mathrm{~cm}$ (Carroll et al., 2018). During each jump, participants positioned a plastic dowel across their shoulders to prevent arm swing which has been reported to influence jump performance (Figure 2) (Harman et al., 1990). Participants performed the SJ by flexing the knees to $90^{\circ}$ and holding for three seconds prior to maximally jumping on a command. In the CMJ, rather than holding the position for three seconds, participants jumped immediately following the knee flexion. Participants then performed the HT in which they completed $10 \mathrm{~s}$ of in-place, bilateral straight leg maximal hopping. Participants were instructed to hop as high as possible without pausing in between and hopped in sync with a digital metronome (Metronome, ONYX Apps) set to $2.2 \mathrm{~Hz}$. Footwear was controlled across all testing days.

\section{Statistical Analysis}

Vertical ground reaction force (vGRF) data were exported and processed via a custom script written in GNU Octave Version 4.3 (Eaton et al., 2016). vGRF data from both force plates were filtered using a $4^{\text {th }}$ order Butterworth lowpass filter (cutoff frequency $=50 \mathrm{~Hz}$ ) and summed. Subsequently, the following variables were calculated and averaged from the three trials of SJ and CMJ $v$ GRF data: peak concentric force $(\mathrm{N})$, rate of force development $(\mathrm{N} / \mathrm{s})$, impulse $(\mathrm{Ns})$, takeoff velocity $(\mathrm{m} / \mathrm{s})$, peak power $(\mathrm{N} / \mathrm{s})$, peak landing force $(\mathrm{N})$, and jump height $(\mathrm{cm})$. Peak power was then normalized using body mass. The eccentric utilization ratio (EUR) was computed from the ratio between CMJ peak power and SJ peak power (McGuigan et al., 2006). Leg stiffness $(k)$ was calculated from $v$ GRF during ground contact time of the $5^{\text {th }} 7^{\text {th }}$ hop from the HT as previously described by Farley et al. (1991). A threshold of $2 \mathrm{~N}$ was used to define the takeoff and landing. The following equations were used to find the resonant period of vibration $(\omega)$ and subsequently $k$ using the period $(T)$ of the $5^{\text {th }}-7^{\text {th }}$ hop and mass $(M)$ :

$$
\begin{gathered}
\omega=\frac{2 \pi}{T} \\
k=M * \omega^{2}
\end{gathered}
$$

Differences in SJ height, CMJ height, EUR, and leg stiffness were assessed for significance using a repeated measures ANOVA over the course of three testing days. Gender was included as a covariate within the ANOVA. Post-hoc analysis was used to test the mean differences for significance between days. The level of significance was set a priori at $\leq 0.05$. Minimal detectable change (MDC) was calculated for $k$ with a $95 \%$ level of confidence using methods previously described (Gardinier et al., 2013; Price et al., 2017).

\section{Results}

Descriptive statistics were computed for all dependent variables (Table 2). Results of the repeated measures ANOVA revealed significant main effects for leg stiffness, but not for SJ height, CMJ height, nor the EUR.

The Mauchly's test for sphericity indicated that the assumption of sphericity for the SJ was met, $\mathrm{X} 2(2)=3.52, p>0.05$, but there was no significant main effect on $\mathrm{SJ}$ height over the three days $\mathrm{F}(2,42)=1.82, p>0.05$.

According to the Mauchly's test, the assumption of sphericity for CMJ height was met, $\mathrm{X} 2(2)=3.03, p>0.05$. There was no significant main effect on CMJ height, $\mathrm{F}(2,42)=3.48, p>0.05$.

The Mauchly's test indicated that the assumption of sphericity for the EUR was met, $\mathrm{X} 2(2)=2.93, p>0.05$, although no significant main effect on the EUR during the three days was found, $\mathrm{F}(2,42)=1.64, p>0.05$.

The Mauchly's test confirmed that the assumption of sphericity was met for $k, \mathrm{X} 2(2)=$ $2.85, p>0.05$. Moreover, there was a significant main effect on $k$ over the three days $\mathrm{F}(2,42)=$ $3.901, \quad p=0.028$ (Figure 3). $k$ decreased significantly from $36.84 \pm 4.96 \mathrm{kN} \cdot \mathrm{m}^{-1}$ to $33.11 \pm$ $8.05 \mathrm{kN} \cdot \mathrm{m}^{-1}$ from $24 \mathrm{~h}$ pre-race to $24 \mathrm{~h}$ post-race $(p$ $=0.025)$ and then increased significantly from $24 \mathrm{~h}$ post-race to $48 \mathrm{~h}$ post-race $\left(36.30 \pm 6.88 \mathrm{kN} \cdot \mathrm{m}^{-1}\right),(p$ $=0.017)$. No significant difference was found from $24 \mathrm{~h}$ pre-race to $48 \mathrm{~h}$ post-race, $p>0.05$. MDC was calculated for test-retest reliability of $k\left(9.06 \mathrm{kN} \cdot \mathrm{m}^{-}\right.$ $\left.{ }^{1}\right)$. Hopping frequency was calculated and tested to verify whether there were deviations throughout the three days. No significant difference in hopping frequency was found during the post-hoc analysis, $\mathrm{F}(2,42)=2.07, p>$ 0.05 . 


\section{Table 1.}

Sex, age, body mass, height and weekly running volume for the 22 participants.

Data expressed as mean \pm standard deviation.

\begin{tabular}{lc}
\hline Sex & $13 \mathrm{M}, 9 \mathrm{~F}$ \\
Age $(\mathrm{yr})$ & $19.5 \pm 1.4$ \\
Mass $(\mathrm{kg})$ & $61.2 \pm 6.3$ \\
Body Height $(\mathrm{m})$ & $1.7 \pm 0.1$ \\
Weekly Running Volume $\left(\mathrm{km} \cdot \mathrm{wk}^{-1}\right)$ & $84.5 \pm 51.2$ \\
\hline
\end{tabular}

Table 2.

Squat jump (SJ) height, countermovement jump (CMJ) height, eccentric utilization ratio (EUR), and leg stiffness $(k)$ were computed over three testing days

(pre-race, $24 \mathrm{~h}$ post-race and $48 \mathrm{~h}$ post-race). *Significant difference between pre-race $(24 \mathrm{~h})$ and post-race (24 h). "Significant difference between post-race $(24 \mathrm{~h})$ and post-race $(48 \mathrm{~h})$.

\begin{tabular}{cccc}
\hline & Pre-Race $(\mathbf{2 4}$ h) & Post-Race $(\mathbf{2 4}$ h) & Post-Race $(\mathbf{4 8 ~ h})$ \\
\hline SJ Height $(\mathrm{cm})$ & $26.89 \pm 5.54$ & $25.99 \pm 5.65$ & $27.19 \pm 5.63$ \\
CMJ Height $(\mathrm{cm})$ & $30.81 \pm 5.79$ & $29.89 \pm 6.06$ & $31.44 \pm 6.47$ \\
EUR & $1.23 \pm 0.1$ & $1.20 \pm 0.09$ & $1.22 \pm 0.1$ \\
$k\left(\mathrm{kN} \cdot \mathrm{m}^{-1}\right)$ & $36.84 \pm 4.96^{*}$ & $33.11 \pm 8.05^{*}, *$ & $36.30 \pm 6.88^{*}$ \\
\hline
\end{tabular}

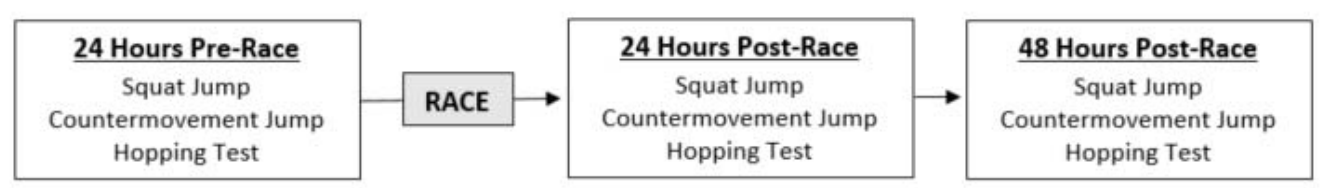

Figure 1.

Twenty-two collegiate cross country runners were tested over four days (24 h pre-race, $24 \mathrm{~h}$ post-race, and $48 \mathrm{~h}$ post-race). Participants performed the same testing battery (squat jump, countermovement jump, and hopping test) under identical testing conditions. 


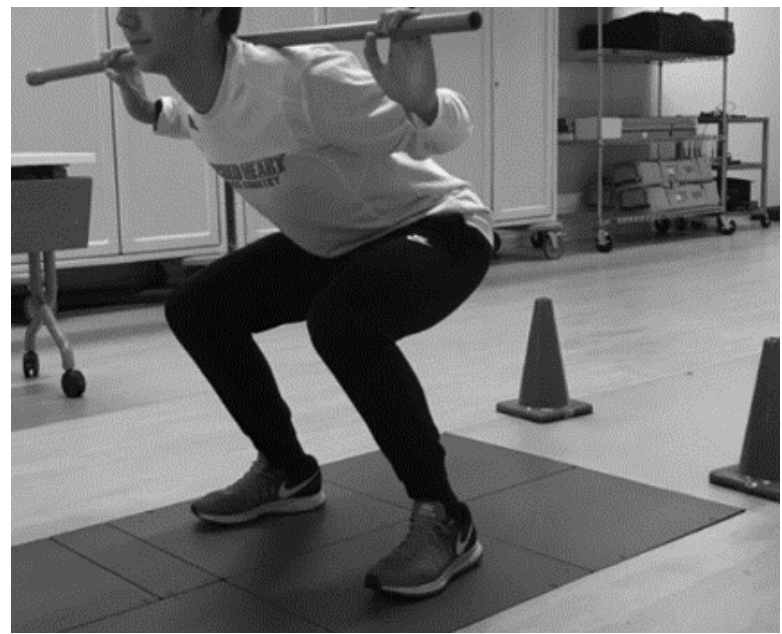

Figure 2.

A plastic dowel was positioned across the shoulders to prevent the arm swing during the squat jump and countermovement jumps.

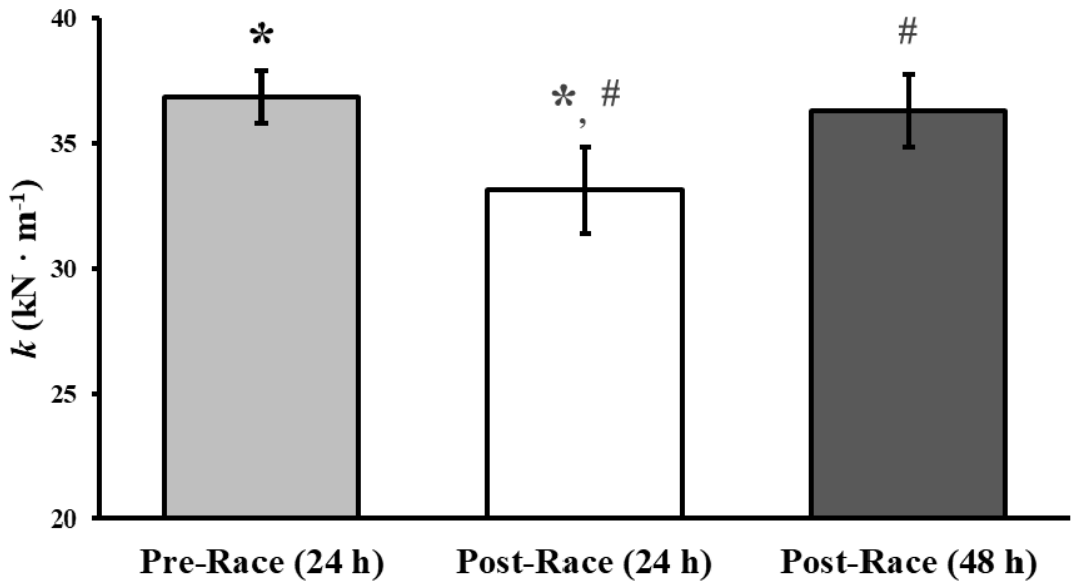

Figure 3.

Leg stiffness ( $k$ ) calculated from ground contact time over three days of testing (24 h pre-race, $24 \mathrm{~h}$ post-race, and $48 \mathrm{~h}$ post-race). Error bars represent standard error of the mean. From $24 \mathrm{~h}$ pre-race to $24 \mathrm{~h}$ post-race $\mathrm{k}$ decreased significantly $\left(36.84 \pm 4.96 \mathrm{kN} \cdot \mathrm{m}^{-1}\right.$ to $\left.33.11 \pm 8.05 \mathrm{kN} \cdot \mathrm{m}^{-1}\right)$ and then increased significantly from $24 \mathrm{~h}$ post-race to $48 \mathrm{~h}$ post-race $\left(36.30 \pm 6.88 \mathrm{kN} \cdot \mathrm{m}^{-1}\right)$. 


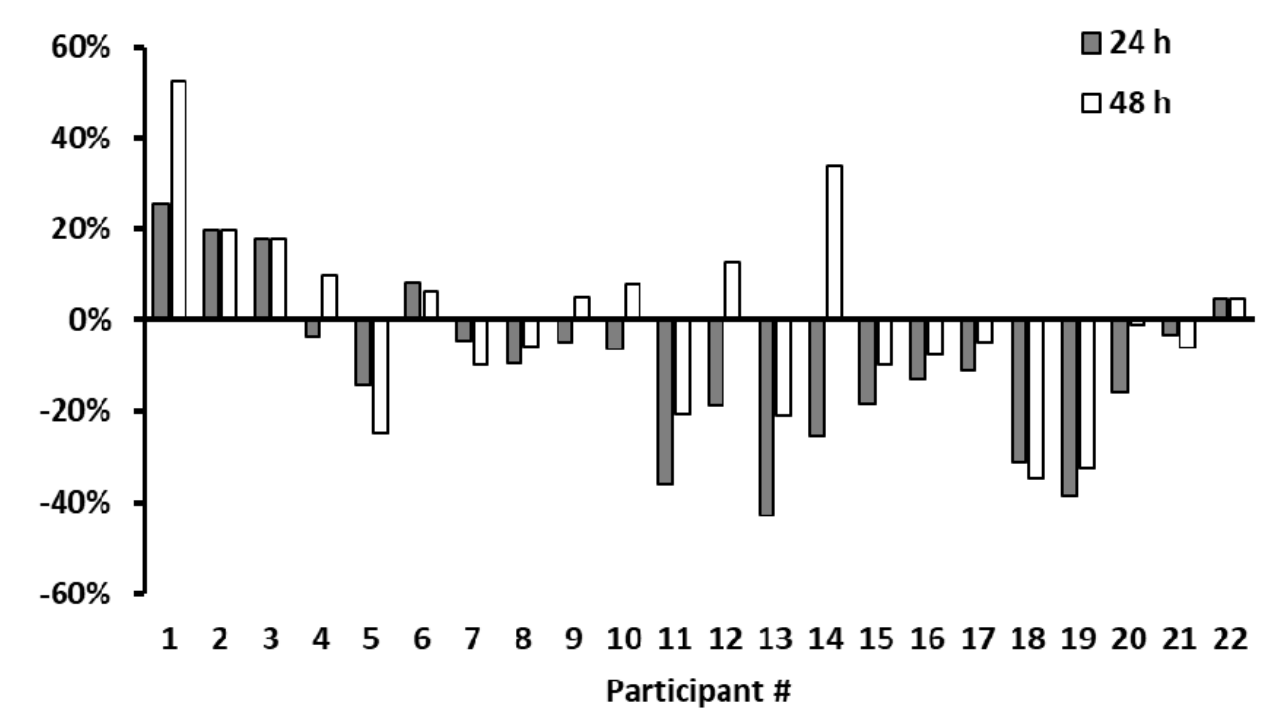

Figure 4.

Percent change of individual responses in leg stiffness $(k) 24 \mathrm{~h}$ and $48 \mathrm{~h}$ post-race. $77.3 \%$ of runners had a reduction in stiffness $24 \mathrm{~h}$ following the race.

\section{Discussion}

This study aimed to observe and record how leg stiffness changed in response to an exhaustive competition. The findings of this study support the hypothesis that lower extremity stiffness significantly decreased in the 24 hours after a cross country race, but returned to baseline within 48 hours post-race. Specifically, k decreased significantly after the race and then increased significantly two days following the race. Although leg stiffness was significantly reduced as a result of racing, no other jumping measures (SJ height, CMJ height, and EUR) demonstrated any significant changes from baseline.

Previous published reports have equivocal findings with regard to the acute changes in leg stiffness as a result of athletic performance (Avela et al., 1999; Horita et al., 1999; Hunter and Smith, 2007; Nicol et al., 2007). For example, Hunter and Smith (2007) reported decreased vertical leg stiffness following a onehour high-intensity run. Nicol et al. (2007) found decreased SSC performance in response to a marathon. SSC performance was assessed using a sprint test, a CMJ, a drop jump, and a forward five hop test. These two studies are in agreement with our results, however, stiffness was only assessed at the end or immediately following the exhaustive bout. Although these researchers did not assess SSC performance in the days following the run, there is evidence that recovery is bimodal with a secondary decline in performance two to three days after exercise (Avela et al., 1999; Horita et al., 1999; Nicol et al., 2007). Faulkner et al. (1993) suggested that the two declines in SSC performance were due to two separate injuries. The first of which was mainly mechanical and the secondary injury was more of an inflammatory response. Given that participants in this study 
were only assessed twice following the race and that the race was substantially shorter than both a marathon and an hour long run, it is hard to ascertain whether the measured leg stiffness decline was the result of a mechanical or inflammatory etiology.

The alterations in leg stiffness pre- and post-race found in this study are in agreement with the previously mentioned reports, but Oliver et al. (2015) reported results that seemingly contradict our findings. They assessed leg stiffness pre- and post-match in a group of youth rugby players over the course of an entire competitive season. They reported that leg stiffness significantly decreased over the course of a season, however, no significant decline was reported when comparing leg stiffness pre- and post-match. While they did not find significance in leg stiffness acutely, their findings support the premise that fatigue has an impact on leg stiffness. It is also possible that acute changes in leg stiffness due to fatigue are more sensitive to a running event than rugby. Possibly supporting this explanation is the fact that they reported acute changes in CMJ performance. Oliver et al. (2015) suggest that the CMJ is a movement specific test for rugby as it mirrors some of the mechanisms involved in the sport. Since running is commonly represented as a simple spring mass model (Farley et al., 1991), it is possible that the HT used in this study was a more runningspecific test. This may also explain why significant differences were only found for leg stiffness and not for the SJ, CMJ, nor the EUR.

There could be several mechanisms which explain why leg stiffness was significantly reduced immediately following a cross country race. A maximal cross country race may elicit decreased neuromuscular performance which influences muscle reflexes as well as muscle and joint stiffness (Komi, 2000). One suggestion for these findings is decreased pre-activation of the lower extremity muscles. Pre-activation, or feedforward muscle activity, plays a primary role in determining leg stiffness (Lehnert et al., 2016; Oliver and Smith, 2010). Nicol et al. (2007) found that following a marathon run, knee flexion immediately following foot contact increased significantly. This may be due to reduced preactivation of the fatigued muscle resulting in a less rapid rebound. Reduced pre-activation has also been found following a $10-\mathrm{km}$ run (Paavolainen et al., 1999) as well as following a marathon (Avela and Komi, 1998). This may suggest lower pre-activation in the runners of this study during the HT following competition. A less rapid rebound due to this may have led to the decreased $\mathrm{k}$ value found in this study. As we did not measure surface electromyography during data collection, there is no possibility to confirm this potential explanation.

Clinically, there may be several important ramifications of the current investigation. Since the HT protocol used to find $\mathrm{k}$ requires very little time and is non-strenuous in nature, it can be easily implemented within a competitive season with no ill-effects on runners. While it is not practical for coaches to use force plates to assess leg stiffness in runners, Lloyd et al. (2009) reported that leg stiffness calculated from a contact mat was comparable to a gold standard. Therefore, it may be possible for coaches to monitor leg stiffness frequently during a training cycle. Since increased leg stiffness has been associated with improved running economy and performance (Arampatzis et al., 2001; Barnes et al., 2013, 2015; Saunders et al., 2006; Spurrs et al., 2003), coaches may want to use leg stiffness to appropriately schedule workouts and rest days. While the aggregate $\mathrm{k}$ significantly decreased and increased in the two days following the race, there were five participants whose $\mathrm{k}$ values did not follow this trend (Figure 4). It is possible that these runners did not provide a maximal effort in the race or that these runners had a faster recovery cycle than the other runners. Alternatively, runners may have required more than one practice session for the HT. Oliver et al. (2014) found that following exercise simulating soccer, leg stiffness increased in half of the participants and decreased in the other half. Pruyn et al. (2013) also suggested that changes in stiffness values throughout a rugby season were found at an individual level. Coaches should be aware that multiple data points will be necessary to understand how runners' leg stiffness responds to training. Multiple data points will also help establish a true baseline prior to making coaching decisions based on leg stiffness values.

There were a few study limitations that should be noted. The male cross country competition was $8 \mathrm{~km}$, while the female 
competition was $5 \mathrm{~km}$. Therefore, it is possible that there was a discrepancy between leg stiffness between the males and females due to different race distances and a potentially different level of fatigue. In addition, we assumed that all participants provided a maximal effort in the race, but this was not assessed. The first two data collection days ( $24 \mathrm{~h}$ pre-race, $24 \mathrm{~h}$ post-race) were tightly controlled with regard to the run that was completed in the preceding 24 hours. However, following the second data collection, participants completed a weekly long run where the run distance and run surface varied between participants. This may have increased the variability of results on the third day of data collection (48 $\mathrm{h}$ post-race), but this had no effect on the preceding data collections. Despite these limitations, since these results were collected within a competitive collegiate cross country season, it increased the ecological validity and potential application of these results.

\section{Conclusion}

In a group of collegiate distance runners, leg stiffness significantly decreased in the 24 hours following a maximal effort cross country race. Despite the lack of sensitivity in the SJ, CMJ, and the EUR, significant changes in $\mathrm{k}$ in this study suggest that leg stiffness may be a valuable assessment metric in monitoring and coaching distance runners. The findings of this study suggest that future research should focus on how leg stiffness fluctuates throughout a microcylce in response to different types of workouts and recovery efforts.

\section{Acknowledgements}

The author kindly thanks J. Vernarelli for assistance with data and statistical analysis.

\section{References}

Arampatzis A, Bruggemann GP, Klapsing GM. Leg stiffness and mechanical energetic processes during jumping on a sprung surface. Med Sci Sport Exer, 2001; 33(6): 923-931

Avela J, Komi PV. Reduced stretch reflex sensitivity and muscle stiffness after long-lasting stretchshortening cycle exercise in humans. Eur J Appl Physiol O, 1998; 78(5): 403-410

Avela J, Kyröläinen H, Komi PV, Rama D. Reduced reflex sensitivity persists several days after long-lasting stretch-shortening cycle exercise. J Appl Physiol, 1999; 86(4): 1292-1300

Barnes KR, Hopkins WG, McGuigan MR, Kilding AE. Warm-up with a weighted vest improves running performance via leg stiffness and running economy. J Sci Med Sport, 2015; 18(1): 103-108

Barnes KR, Hopkins WG, McGuigan MR, Kilding AE. Effects of Different Uphill Interval-Training Programs on Running Economy and Performance. Int J Sport Physiol, 2013; 8(6): 639-647

Butler RJ, Crowell HP, Davis IM. Lower extremity stiffness: implications for performance and injury. Clin Biomech, 2003; 18(6): 511-517

Carroll KM, Bernards JR, Bazyler CD, Taber CB, Stuart CA, DeWeese BH, Sato K, Stone MH. Divergent Performance Outcomes Following Resistance Training Using Repetition Maximums or Relative Intensity. Int J Sport Physiol, 2019; 14(1): 46-54

Cavagna GA, Franzetti P, Heglund NC, Willems P. The determinants of the step frequency in running, trotting and hopping in man and other vertebrates. J Physiol, 1998; 399: 81-92

Conley DL, Krahenbuhl GS. Running economy and distance running performance of highly trained athletes. Med Sci Sport Exer, 1980; 12(5): 357-360

Conley DL, Krahenbuhl GS, Burkett LN, Millar AL. Following Steve Scott: Physiological Changes Accompanying Training. Physician Sportsmed, 1984; 12(1): 103-106

Farley CT, Blickhan R, Saito J, Taylor CR. Hopping frequency in humans: a test of how springs set stride frequency in bouncing gaits. J Appl Physiol, 1991; 71(6): 2127-2132

Faulkner JA, Brooks SV, Opiteck JA. Injury to Skeletal Muscle Fibers During Contractions: Conditions of Occurrence and Prevention. Phys Ther, 1993; 73(12): 911-921 
Gardinier ES, Manal K, Buchanan TS, Snyder-Mackler L. Minimum detectable change for knee joint contact force estimates using an EMG-driven model. Gait Posture, 2013; 38(4): 1051-1053

Harman EA, Rosenstein MT, Frykman PN, Rosenstein RM. The effects of arms and countermovement on vertical jumping. Med Sci Sport Exer, 1990; 22(6): 825-833

Horita T, Komi PV, Nicol C, Kyröläinen H. Effect of exhausting stretch-shortening cycle exercise on the time course of mechanical behaviour in the drop jump: possible role of muscle damage. Eur J Appl Physiol O, 1999; 79(2): 160-167

Hunter I, Smith GA. Preferred and optimal stride frequency, stiffness and economy: changes with fatigue during a 1-h high-intensity run. Eur J Appl Physiol, 2007; 100(6): 653-661

Komi PV. Stretch-shortening cycle: a powerful model to study normal and fatigued muscle. J Biomech, 2007; 33(10): 1197-1206

Lehnert M, De Ste Croix M, Zaatar A, Hughes J, Varekova R, Lastovicka O. Muscular and neuromuscular control following soccer-specific exercise in male youth: Changes in injury risk mechanisms. Scand J Med Sci Spor, 2016; 27(9): 975-982

Lloyd RS, Oliver JL, Hughes MG, Williams CA. Reliability and validity of field-based measures of leg stiffness and reactive strength index in youths. J Sport Sci, 2009; 27(14): 1565-1573

McGuigan MR, Doyle TL, Newton M, Edwards DJ, Nimphius S, Newton RU. Eccentric Utilization Ratio: Effect of Sport and Phase of Training. J Strength Cond Res, 2006; 20(4): 992-995

Morin JB, Jeannin T, Chevallier B, Belli A. Spring-Mass Model Characteristics During Sprint Running: Correlation with Performance and Fatigue-Induced Changes. Int J Sports Med, 2006; 27(02): 158-165

Nicol C, Komi PV, Marconnet P. Fatigue effects of marathon running on neuromuscular performance. Scand J Med Sci Spor, 2007; 1(1): 10-17

Oliver JL, Smith PM. Neural control of leg stiffness during hopping in boys and men. J Electromyogr Kines, 2010; 20(5): 973-979

Oliver JL, De Ste Croix MB, Lloyd RS, Williams CA. Altered neuromuscular control of leg stiffness following soccer-specific exercise. Eur J Appl Physiol, 2014; 114(11): 2241-2249

Oliver JL, Lloyd RS, Whitney A. Monitoring of in-season neuromuscular and perceptual fatigue in youth rugby players. Eur J Sport Sci, 2015; 15(6): 514-522

Paavolainen L, Nummela A, Rusko H, Häkkinen K. Neuromuscular characteristics and fatigue during $10 \mathrm{~km}$ running. Int J Sports Med, 1999; 20(8): 516-521

Price PDB, Gissane C, Cleather DJ. Reliability and Minimal Detectable Change Values for Predictions of Knee Forces during Gait and Stair Ascent Derived from the FreeBody Musculoskeletal Model of the Lower Limb. Front Bioeng Biotechnol, 2017; 5: 74

Pruyn EC, Watsford ML, Murphy AJ, Pine MJ, Spurrs RW, Cameron ML, Johnston RJ. Seasonal Variation of Leg Stiffness in Professional Australian Rules Footballers. J Strength Cond Res, 2013; 27(7): 1775-1779

Saunders PU, Telford RD, Pyne DB, Peltola EM, Cunningham RB, Gore CJ, Hawley JA. Short-term plyometric training improves running economy in highly trained middle and long distance runners. $J$ Strength Cond Res, 2006; 20(4): 947-954

Spurrs RW, Murphy AJ, Watsford ML. The effect of plyometric training on distance running performance. Eur J Appl Physiol, 2003; 89(1): 1-7

\section{Corresponding author:}

\section{Matthew F Moran}

Sacred Heart University, College of Health Professions,

Department of Physical Therapy \& Human Movement Science,

Motion Analysis Laboratory. 5151 Park Avenue. Fairfield, USA.

Phone: 203-365-4703; Fax: 203-365-4723; Email: moranm@sacredheart.edu

(c) Editorial Committee of Journal of Human Kinetics 